\title{
COMPARISON OF PREDICTIVE VALUE OF GLASGOW COMA SCALE VERSUS FULL OUTLINE OF UNRESPONSIVENESS (FOUR) SCALE ON THE OUTCOME OF HEAD INJURY PATIENTS ADMITTED TO THE INTENSIVE CARE UNIT
}

\author{
B. V. Mahesh Babu', Snehalatha Bhashyam², B. Sowbhagya Lakshmi ${ }^{3}$
}

${ }^{1}$ Associate Professor, Department of Anaesthesiology and Critical Care, Rangaraya Medical College, Government General Hospital, Kakinada.

${ }^{2}$ Assistant Professor, Department of Anaesthesiology and Critical Care, Rangaraya Medical College, Government General Hospital, Kakinada.

${ }^{3}$ Professor and HOD, Department of Anaesthesiology and Critical Care, Rangaraya Medical College, Government General Hospital, Kakinada.

\section{ABSTRACT}

\section{BACKGROUND}

The Glasgow Coma Scale (GCS) is a widely accepted tool and the gold standard for determining the severity of head injury (HI) patients, but it has some limitations. The full outline of unresponsiveness (FOUR) score is a novel coma scale developed to overcome the limitations of the GCS. The aim of the study was to compare the ability of the FOUR score and GCS in predicting mortality and outcome in patients with head injury (HI).

\section{MATERIALS AND METHODS}

This prospective, observational study was conducted on 98 adult patients with head injury (HI) who were evaluated using GCS and FOUR score. Scores obtained for each scale were recorded. The area under receiver operating characteristic (ROC) curve was used for predicting in-hospital mortality for GCS and FOUR score. For further analysis, the patients were divided into two groups, groupI FOUR and GCS $<7$ and group-II scores $>7$. Both the scores were compared with outcome parameters like Glasgow Outcome Scale, duration of ventilation, duration of intensive care unit stay, length of hospital stay.

\section{RESULTS}

Of all patients 68 survived (69.38\%) and 30 died (30.6\%). Mean GCS score among alive was $9.46 \pm 3.82$ and among the dead was $5.36 \pm 2.42(\mathrm{P}<0.0001)$, mean FOUR score among alive was $9.18 \pm 3.42$ and among dead was $4.98 \pm 3.21(\mathrm{P}<0.0001)$. For inhospital mortality, area under receiver operating characteristic curve (AUC) was 0.860 for FOUR score and 0.796 for GCS, (p= 0.026). Outcome parameters showed better correlation with group I FOUR score as compared to GCS (p value=0.038, $0.034,0.029$ and 0.045 respectively ( $\mathrm{p}<0.05$ significant).

\section{CONCLUSION}

FOUR score is a reliable, sensitive and valid tool, superior to the GCS with high accuracy in predicting mortality and outcome in patients with head injury (HI).

\section{KEYWORDS}

Full Outline of Unresponsiveness (FOUR) Scale, Glasgow Coma Scale, Head Injury Patients, Outcome-Predictions.

HOW TO CITE THIS ARTICLE: Babu BVM, Bhashyam S, Lakshmi SB. Comparison of predictive value of Glasgow Coma Scale versus Full Outline of Unresponsiveness (FOUR) scale on the outcome of head injury patients admitted to the intensive care unit. J. Evolution Med. Dent. Sci. 2017;6(28):2300-2304, DOI: 10.14260/Jemds/2017/495

\section{BACKGROUND}

Head injury (HI), also termed 'traumatic brain injury' (TBI) is one of the major causes of trauma related mortality and severe disability worldwide. It is estimated that nearly 1.5 million people die due to head injuries each year and millions of people need rehabilitation services. Initial assessment of severity of injury in patients of traumatic brain injury is the primary guide for treatment programme and predicting outcome of trauma.1,2 The gold standard tool to determine

Financial or Other, Competing Interest: None.

Submission 01-03-2017, Peer Review 24-03-2017,

Acceptance 31-03-2017, Published 06-04-2017.

Corresponding Author:

Dr. Snehalatha Bhahsyam,

H. No. 8-11-18/1,

Opp. Indian Red Cross Society,

Red Cross Street, Gandhi Nagar,

Kakinada-533004.

E-mail: snehabhashyam@gmail.com

DOI: $10.14260 /$ jemds $/ 2017 / 495$

\section{(c) $($ ) $\ominus$}

the severity of head injury is Glasgow Coma Scale (GCS) ${ }^{3}$ which was invented by Graham Teasdale and Bryan J. Jennett in 1974 and revised in 1976. It has three components including (1) eye or visual, (2) motor and (3) verbal, the scores being 4, 5 and 6 respectively, totally included a range of 3-15, three being the worst. It has universal acceptance because of its simplicity, 4 high level of inter-observer reliability, ${ }^{5}$ high accuracy in prediction of outcome, mortality and morbidity. But has its own limitations when applied to intubated patients. ${ }^{6}$ In addition, it also did not assess brain stem reflexes. ${ }^{7}$ To overcome these limitations, Wijdicks and co-researchers ${ }^{8,9}$ designed a scoring system in 2005 called the Full Outline of Unresponsiveness (FOUR) score as an alternative to the GCS to evaluate the awareness of patients with severe brain damage. Full Outline of Unresponsiveness score has four components including (1) eye or visual, (2) motor, (3) brain stem reflex and (4) respiratory pattern. Each of the components carries five parameters with total points ranging from 0 to 4 and potential scores ranging from 0 to 16 [Table 1]. It is applicable for both traumatic ${ }^{10}$ and non- 
traumatic brain injuries. ${ }^{11}$ Unlike the GCS it does not rely on verbal response and is hence more useful in intubated patients. ${ }^{12,13}$ Increased mortality and morbidity is associated with low FOUR scores. Unlike the GCS, FOUR score can identify locked in syndrome, uncal herniation, and the beginning of the vegetative state, where the verbal component of the GCS, cannot be used in intubated patients. ${ }^{14,15}$ This study was thus designed to compare the FOUR score with GCS for prognostication of patients with traumatic head injuries and unique feature of our study was to analyse the impact of these scores on outcome parameters as Glasgow outcome scale, duration of ventilator days, duration of stay in intensive care unit, length of hospital stay and in-hospital mortality.

\section{MATERIALS AND METHODS}

This prospective, observational study was conducted over a period of nine months from March 2016 to November 2016 in the neurosurgical intensive care unit of a tertiary care government general and teaching hospital. After obtaining institutional ethical committee approval and written consent from the patient attendants, data was collected and analysed from a total of 98 patients who met the inclusion criteria. Sampling done was based on the convenience method. The inclusion criteria were as following: patients with head injury, age range between 20 and 65 years, survival 24 hours after admission to intensive care unit. Furthermore, the exclusion criteria of the study included patients with underlying disorders, addiction, taking sedative drugs like tranquilisers or neuromuscular blocking agents before measurement and family or hereditary history of neuromuscular diseases.

All patients were assessed within first 24 hours of admission, either in emergency room or neurosurgical intensive care unit using both Glasgow Coma Scale and full outline of unresponsiveness score. Data was collected using a predetermined proforma. The patients were regularly assessed thereafter in the intensive care unit using both GCS and FOUR scales and scores obtained for each scale were recorded by an anaesthesia resident. Assessment of patients survival or mortality continued until their discharge or death. The outcome parameters assessed were the duration of ventilation, duration of intensive care unit stay, length of hospital stay, Glasgow outcome scale and in-hospital mortality. For determining outcome of traumatic brain injury, Glasgow outcome scale is an accepted tool with a high validity and reliability with five levels: complete recovery $=5$, mild disability $=4$, severe disability $=3$, coma $=2$, and expiry $=1$. Glasgow outcome scale $<3$ was defined as poor outcome.

Finally, collected data was analysed using SPSS-17 software and GraphPad.com software. Descriptive statistics were used to analyse data, including mean, standard deviation, and frequency percentage. Student's t-test was used to compare the scores and inferential statistics test included the Youden index and diagnostic values (TP, TN, FP, and FN) were used. In order to compare the prediction power of the two scores receiver operating characteristic (ROC) curve was plotted, and areas under curve for both scores were compared. A p-value $<0.05$ was considered statistically significant.

\section{RESULTS}

In this study, 98 intensive care unit patients with head injuries and age range from 20-65 years with mean age $34.72 \pm 12.47$ years were assessed. $93.87 \%$ (92) of patients were males and remaining $6.12 \%$ (6) of patients were females. Among all the patients with head injuries, in terms of admissions, $24(24.48 \%)$ patients were with epidural haematoma, 44 (44.89\%) with subdural haematoma, 11 (11.22\%) had subarachnoid haematoma, and 19 (19.38\%) had a haematoma in brain tissue. At the time of admission, GCS value among the patients varied from 3 to 15 , with a mean value of $9.85 \pm 4.02$ and FOUR score varied from 1 to 16 , with a mean value of $11.26 \pm 4.00$ [Table 2].

92 patients required intubation and were on mechanical ventilation. The duration of ventilatory support and number of days of intensive care unit stay ranged from 3-26 days and 3-33 days with a mean of $10.52 \pm 6.81$ days and $13.86 \pm 9.92$ days respectively. The total duration of hospital stay ranged from 3-42 days with mean of $24.10 \pm 14.32$ days.

Of all patients, 68 survived (69.38\%) and 30 died (30.6\%). Mean GCS score among alive was $9.46 \pm 3.82$ and among the dead was $5.36 \pm 2.42(\mathrm{P}<0.0001)$. Mean FOUR score among alive was $9.18 \pm 3.42$ and among dead was 4.98 \pm 3.21 ( $\mathrm{P}<0.0001)$. Both GCS and FOUR scores were lower among dead than among alive, and they were statistically significant. [Table 3].

The diagnostic indicators for predicting mortality like sensitivity, specificity, positive predictive value, negative predictive value, positive likelihood ratio and accuracy of GCS were $75.94 \%, 77.83 \%, 60.53 \%, 88.53 \%$, and $3.34 \%, 75.55 \%$ respectively and that for FOUR score was 79.94, 81.63\%, $90.33 \%, 60.53 \%, 3.97 \%$ and $79.49 \%$, respectively. [Table 4]. Frequency of distribution of Glasgow Come Scale (range: 315) and Full Outline of Unresponsiveness (FOUR) scores (range: 0-16) among the study population was represented in Figures 1 and 2.

Discrimination for GCS and FOUR score was tested by the area under the receiver operating characteristics (ROC) curve which was 0.796 for GCS and 0.860 for FOUR score respectively ( $p=0.026$ ) [Figures 3 and 4 ]. The best cut-off point calculated from Youden index was 7 for GCS and 8 for FOUR score.

For analysing outcome parameters like Glasgow outcome scale, duration of ventilator days, duration of stay in intensive care unit and length of hospital stay, all the patients were separated into two groups, group I with FOUR and GCS score less than or equal to 7 and group II with scores more than 7 . The mean values of both the scores in group-I were compared with outcome parameters as Glasgow outcome scale $(<3)$, duration of ventilator days, days of intensive care unit stay and days of hospital stay using student $t$ test which exhibited better correlation with group I FOUR score as compared to GCS ( $\mathrm{p}$ value $=0.038,0.034,0.029$ and 0.045 respectively) which was statistically significant. (P value $<0.05$ ). Further in group II, the outcome correlation between FOUR and GCS was not statistically significant ( $\mathrm{p}$ value $=0.105,0.125,0.223$ and 0.369 respectively) as shown in Table 5 . 


\begin{tabular}{|c|c|c|}
\hline Groups & $\begin{array}{c}\text { Neurological Scores } \\
\text { Mean } \mathbf{~ S D} \\
\mathbf{n = 9 8}\end{array}$ & $\mathbf{p}=\mathbf{9}$ \\
\cline { 1 - 2 } $\begin{array}{c}\text { Glasgow } \\
\text { (GCS) }\end{array}$ & $9.85 \pm 4.02$ & \\
\hline $\begin{array}{c}\text { Full Outline of } \\
\text { Unresponsiveness } \\
\text { (FOUR) }\end{array}$ & $11.26 \pm 4.00$ & \\
\hline \multicolumn{2}{|c|}{ Table 1. Values of Baseline Characteristics } \\
\hline
\end{tabular}

Data expressed as mean (SD) or ratio or absolute numbers Student-t-test

${ }^{*}$ p value $<0.05$ statistically significant

SD- Standard Deviation

\begin{tabular}{|c|c|c|c|}
\hline \multirow{2}{*}{ Groups } & \multicolumn{2}{|c|}{ Outcome } & \multirow{2}{*}{ p=value } \\
\cline { 2 - 3 } & $\begin{array}{c}\text { Non-survivors } \\
\text { Mean } \pm \text { SD }\end{array}$ & $\begin{array}{c}\text { Survivors } \\
\text { Mean } \pm \text { SD }\end{array}$ & \\
\hline GCS & $5.36 \pm 2.42$ & $9.46 \pm 3.82$ & $\mathrm{p}=0.0001^{* *}$ \\
\hline FOUR & $4.98 \pm 3.21$ & $9.18 \pm 3.42$ & $\mathrm{p}=0.0001^{* *}$ \\
\hline
\end{tabular}

Table 2. Mean Values of FOUR and GCS Score among the Non-survivors and Survivors
Data expressed as mean (SD) or ratio or absolute numbers Student-t-test

** Statistically highly significant

SD- Standard Deviation

\begin{tabular}{|c|c|c|}
\hline Scale/Indicator & $\begin{array}{c}\text { Glasgow } \\
\text { Coma Scale } \\
\text { (GCS) }\end{array}$ & Four Score \\
\hline Sensitivity & $75.94 \%$ & $79.94 \%$ \\
\hline Specificity & $77.83 \%$ & $81.63 \%$ \\
\hline Positive predictive value & $60.53 \%$ & $90.33 \%$ \\
\hline $\begin{array}{c}\text { Negative predictive } \\
\text { value }\end{array}$ & $88.53 \%$ & $60.53 \%$ \\
\hline Positive Likelihood ratio & $3.34 \%$ & $3.97 \%$ \\
\hline Accuracy & $75.55 \%$ & $79.49 \%$ \\
\hline
\end{tabular}

Data expressed in percent (\%) or ratio or absolute numbers.

\begin{tabular}{|c|c|c|c|c|c|c|}
\hline \multirow{2}{*}{$\begin{array}{c}\text { Outcome } \\
\text { Parameters }\end{array}$} & \multicolumn{2}{|c|}{ Group I } & \multirow[b]{2}{*}{ p-value } & \multicolumn{2}{|c|}{ Group II } & \multirow[b]{2}{*}{ p-value } \\
\hline & $\begin{array}{c}\text { GCS Score }<7 \\
\text { Mean + SD }\end{array}$ & $\begin{array}{c}\text { FOUR Score }<7 \\
\text { Mean + SD }\end{array}$ & & $\begin{array}{c}\text { GCS Score >7 } \\
\text { Mean + SD }\end{array}$ & $\begin{array}{c}\text { FOUR Score }>7 \\
\text { Mean + SD }\end{array}$ & \\
\hline GOS $(<3)$ & $2.95 \pm 1.19$ & $2.31 \pm 1.08$ & $0.038^{*}$ & $3.98 \pm 2.70$ & $3.31 \pm 2.05$ & $\mathrm{p}=0.105$ \\
\hline Ventilator days & $10.63 \pm 5.23$ & $9.86 \pm 4.08$ & $0.034^{*}$ & $6.04 \pm 3.10$ & $5.31 \pm 2.45$ & $\mathrm{p}=0.125$ \\
\hline ICU stay days & $14.56 \pm 7.81$ & $12.31 \pm 6.50$ & $0.029 *$ & $11.17 \pm 4.98$ & $10.36 \pm 4.31$ & $\mathrm{p}=0.223$ \\
\hline Hospital stay (days) & $26.20 \pm 12.08$ & $29.89 \pm 13.48$ & $0.045^{*}$ & $22.42 \pm 10.81$ & $19.17 \pm 9.32$ & $p=0.369$ \\
\hline
\end{tabular}

Data expressed as mean (SD) or ratio or absolute numbers

Student-t-test

SD- Standard Deviation

*Statistically significant

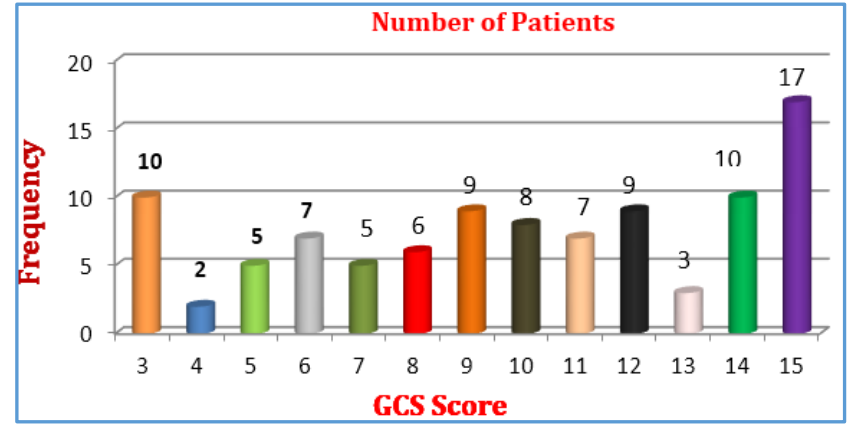

Figure 1. Frequency of Glasgow Coma Scale (GCS) Scores (range: 3-15) among the Study Population

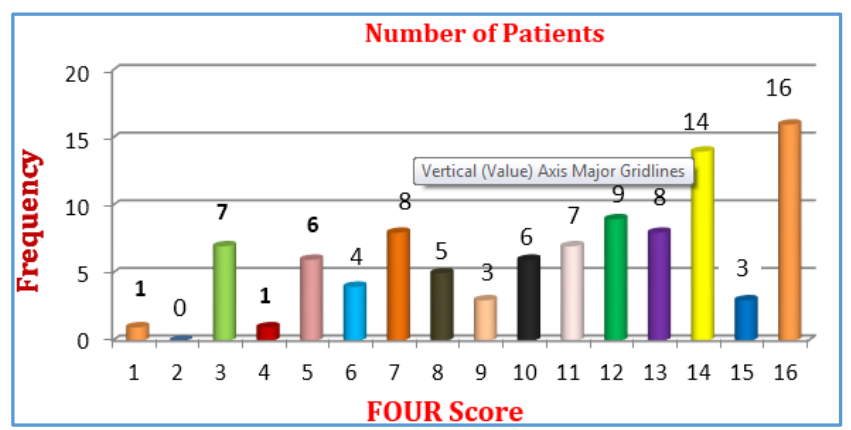

Figure 2. Frequency of Full Outline of Unresponsiveness (FOUR) Scores (range: 1-16) among the Study Population

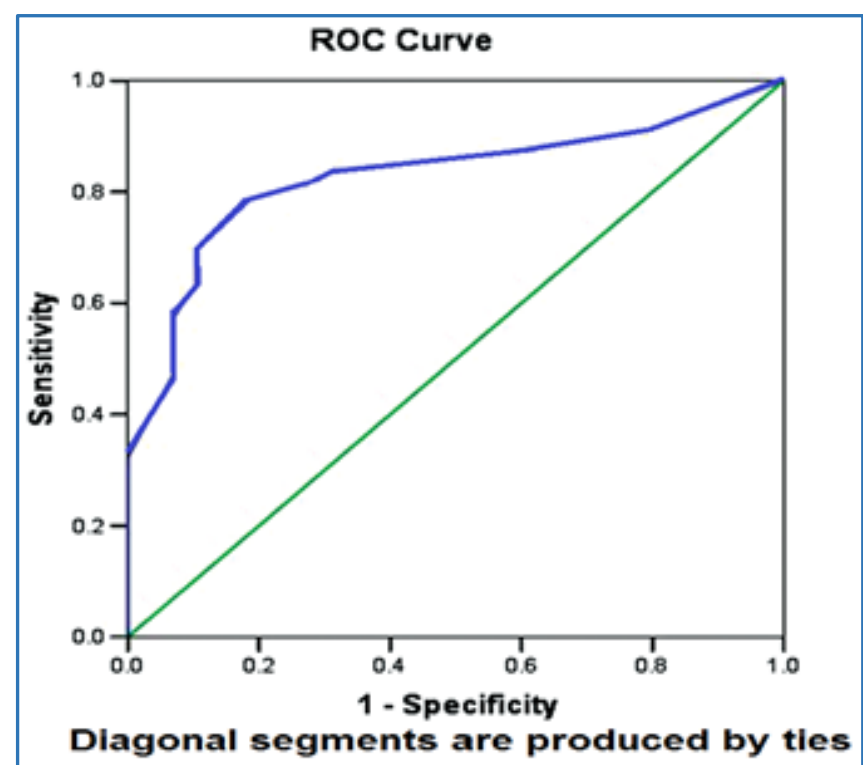

Figure 3. Receiver Operating Characteristic Curve (ROC) of Glasgow Coma Scale (Area under the Curve =0.796) 


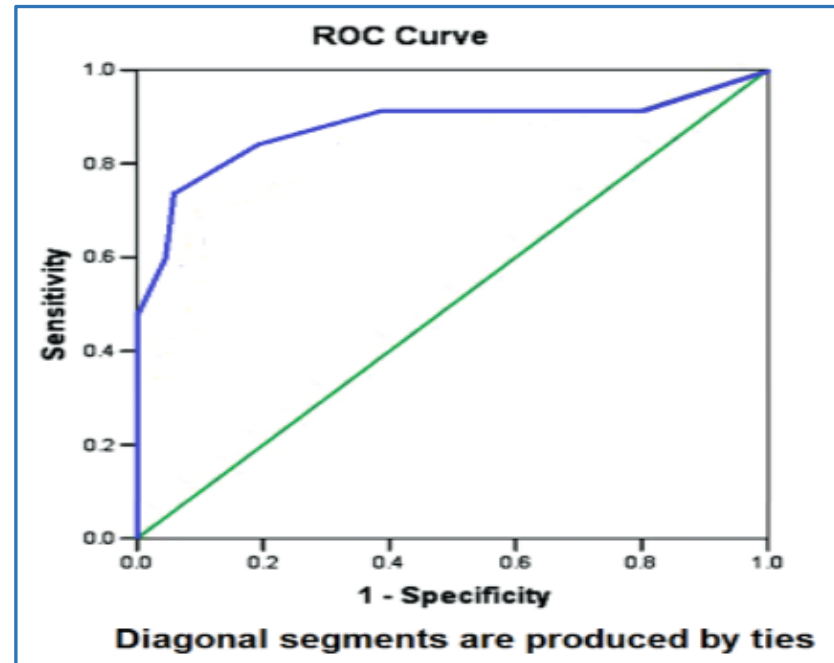
Figure 4. Receiver Operating Characteristic Curve
(ROC) of Full Outline of Unresponsiveness
(Area under the Curve $=0.860$ )

\section{DISCUSSION}

Numerous scoring systems have been defined which are useful in predicting patients' outcome by evaluating their level of consciousness. Recognising failures of GCS in assessing patients' level of consciousness, Wijdicks and coresearchers 8,9 proposed the Full Outline of Unresponsiveness Scale. FOUR score is simple to use, it assesses depth of coma in greater details compared to GCS. This was a prospective, observational study undertaken to find whether full outline of unresponsiveness score can be an effective tool in assessing patients with head injury when compared to GCS.

FOUR score classification in the range of 0-7 means high mortality, 8-14 means intermediate mortality and 15-16 indicates low mortality rate. ${ }^{12}$

There was no meaningful difference among the patient's age, gender and kinds of injuries to outcome in our study which corresponds to the study of Izadi and co-researchers. ${ }^{16}$ Our samples mostly included young men at active age who are more prone for their high risky behaviours which is in consonance with the studies of Farid and co-authors. ${ }^{17}$

Overall mortality observed in our study was $30.61 \%$ which is nearer to the study of Kishor Khanal et al ${ }^{18}$ who compared outcome predictions by the Glasgow Coma Scale and the full outline of unresponsiveness score in the neurological and neurosurgical patients in the intensive care unit, wherein overall mortality observed was $29.9 \%$. Also the receiver operating characteristic (ROC) curve for prediction of in-hospital mortality for Full Outline of Unresponsiveness score showed higher curve level than GCS.

Jennifer Cohen and co-researchers ${ }^{19}$ have reported a higher predictive value for the FOUR score than the GCS in intensive care unit patients. The results of our study also indicate that FOUR is a correct predictor of mortality in patients with traumatic brain injuries when compared to GCS.

Wijdicks and co-researchers ${ }^{8}$ considered 7 and 9 as the best cut-off point for GCS and FOUR score, respectively, while cut-off point in our study was 7 and 8 for GCS and FOUR score respectively, which was nearer to their study.

Marcati E and co-authors ${ }^{20}$ in their study demonstrated that likelihood ratio was higher in FOUR scale than GCS score which better predicts outcome of the head injury patients. The results of our study correlated with their study.

In this study, we compared GCS and FOUR score with outcome parameters like duration of ventilator days, duration of stay in ICU and length of hospital stay using Glasgow Outcome Scale. For this the patients of head injury were divided into two groups. Group I included patients with GCS and FOUR score $<7$ or equal and group II with GCS and FOUR scores $>7$. The results of our study showed an excellent circumstantial validity between the novel FOUR score and the well-known GCS score in the lower score range, with a significant difference between the two scores but in the higher range, FOUR score is a better predictor of Glasgow Outcome Scale $>3$, limited ventilator days and reduced intensive care unit stay.

Phuping A and co-authors ${ }^{\mathbf{2}}$ in their study demonstrated prediction of discharge outcome with the Full Outline of Unresponsiveness (FOUR) score in neurosurgical patients. The findings of their study were similar to our study.

The limitation of our study- $93.87 \%$ of the study population were intubated, hence the verbal sub-component of GCS was not scored and counted as 1.

\section{CONCLUSION}

Based on the study results it can be concluded that FOUR score is a novel, more precise, sensitive and specific tool for predicting mortality and outcome in patients of head injuries. By utilising brain stem reflexes and respiratory pattern, this scale provides an accurate and correct assessment than GCS in patients of coma. Therefore, FOUR score is recommended as a valid tool, superior to GCS for evaluation and prognostication of head injury patients.

\section{ACKNOWLEDGMENTS}

We, the authors of the article, are thankful to the relatives of the patients for their help and cooperation and also the personnel of intensive care unit, Department of Anaesthesiology and Critical Care, Rangaraya Medical College, Government General Hospital, Kakinada, Andhra Pradesh for their assistance in this study.

\section{REFERENCES}

[1] Delney KA, Gold FL. Management of the multiply injured or intoxicated. In: Cooper P, Golfinos J. eds. Head injury. $4^{\text {th }}$ edn. New York: McGraw-Hill 2000:4162.

[2] Valadka AB, Narayan RK. Emergency room management of the head injury patient. In: Narayan R, Povlishock J. eds. Neurotrauma. Newyork: McGrawHill 1996:119-35.

[3] The Brain Trauma Foundation. The American association of neurological surgeons. The joint section on neurotrauma and critical care. Glasgow Coma Scale Score. J Neurotrauma 2000;17(6-7):563-71.

[4] Fischer J, Mathieson C. The history of the Glasgow Coma Scale: Implications for practice. Crit Care Nurs Q 2001;23(4):52-8.

[5] Buechler CM, Blostein PA, Koestner A, et al. Variation among trauma centers' calculation of Glasgow Coma Scale score: results of a national survey. J Trauma 1998;45(3):429-32. 
[6] Teasdale G, Jennett B. Assessment of coma and impaired consciousness. A practical scale. Lancet 1974;304(7872):81-4.

[7] Born JD, Hans P, Dexters G, et al. Practical assessment of brain dysfunction in severe head trauma. Neurochirurgie 1982;28(1):1-7.

[8] Wijdicks EF, Bamlet WR, Maramattom BV, et al. Validation of a new coma scale: the FOUR score. Ann Neurol 2005;58(4):585-93.

[9] Wijdicks EF. Clinical scales for comatose patients: the Glasgow Coma Scale in historical context and the new FOUR score. Rev Neurol Dis 2006;3(3):109-17.

[10] Sadaka F, Patel D, Lakshmanan R. The FOUR score predicts outcome in patients after traumatic brain injury. Neurocrit Care 2012;16(1):95-101.

[11] Idrovo L, Fuentes B, Medina J, et al. Validation of the FOUR score (Spanish Version) in acute stroke: an interobserver variability study. Eur Neurol 2010;63(6):364-9.

[12] Akavipat P. Endorsement of the FOUR score for consciousness assessment in neurosurgical patients. Neurol Med Chir (Tokyo) 2009;49(12):565-71.

[13] Knaus WA, Wagner DP, Zimmerman JE, et al. Variations in mortality and length of stay in intensive care units. Ann Intern Med 1993;118(10):753-61.
[14] Wolf CA, Wijdicks EF, Bamlet WR, et al. Further validation of the FOUR score coma scale by intensive care nurses. Mayo Clin Proc 2007;82(4):435-8.

[15] Laureys S, Pellas F, van Eeckhout P, et al. The lockedin syndrome: What is it like to be conscious but paralyzed and voiceless? Prog Brain Res 2005;150: 495-511.

[16] Avanji FSI, Fakharian E, Alavi NM. Outcome of factors related to traumatic brain injuries among the patients hospitalized in intensive care unit. KUMS Journal (FEYZ) 2010;14(2):112-9.

[17] Farid S, Darshan P, Rekha L. The four score predicts outcome in after traumatic brain injury. Neuocrit Care 2011;15:250-6.

[18] Khanal K, Bhandari SS, Shrestha N, et al. Comparison of outcome predictions by the Glasgow coma scale and the full outline of unresponsiveness score in the neurological and neurosurgical patients in the Intensive Care Unit. Indian Journal of Critical Care Medicine August 2016:20(8):473-6.

[19] Cohen J. Interrater reliability and predictive validity of the FOUR score coma scale in a pediatric population. J Neruosci Nursing 2009;41(5):261-7.

[20] Marcati E, Ricci S, Casalena A, et al. Validation of the Italian version of a new coma scale: the FOUR score. Intern Emerg Med 2012;7(2):145-52. 